\title{
The standard of data quality control technology based on the share of rural science and technology data
}

\author{
Dan Wang $^{1, \mathrm{a}}$ Xiaorong Yang ${ }^{1, \mathrm{~b}} \quad$ Jian Ma $^{1, \mathrm{c}}$ Yang Sun ${ }^{1, \mathrm{~d}}$ \\ ${ }^{1}$ Institute of Agricultural Information, Chinese Academy of Agricultural Sciences, Beijing \\ 100081, China; \\ 2 Key Laboratory of Agricultural Information Service Technology（2006-2010）, Ministry of \\ Agriculture, The People 's Republic of China \\ àwangdan01@caas.cn, byangxiaorong@caas.cn, ${ }^{\mathrm{c}}$ majian@caas.cn, ${ }^{\mathrm{d}}$ sunyang@caas.cn
}

\begin{abstract}
The standard of data quality control technology based on the share of rural science and technology data is one of the important standards to share network information source. In the paper, data quality control system is presented. The technical specification of data quality control in the data collection, data input, subject indexing, data storage construction, data description and data unit was prescribed, too. At last, it produces workflow and estimate index of data quality control.
\end{abstract}

Keywords: rural science and technology data, data quality control, technical specification, data sharing

\section{Introduction}

The construction of rural science and technology data sharing platform (referred to as a Shared Platform) is an important part of agricultural informatization, which is an effective way to solve rural technology "islands of information" and "last mile" problem and the service to "agriculture, rural areas and farmers". "Shared Platform" has a variety of data types and a huge amount of data, creating a standard of data quality control technology based on the share of rural science and technology data to effectively control the quality of the data is very necessary in the process of data collection, processing and retrieval using.

\section{2 "Shared Platform" data quality control system}

"Shared platform" data quality control system includes two parts of data quality control management specifications and technical specifications.

Data quality control management department is composed by the quality control system administration and quality control technology group. The former is mainly responsible for organization and management of quality control standards. The latter is mainly responsible for the technical specifications of quality control of data. 
"Quality control technical specifications" is the main indicator and basis for controlling rural science data quality, its main contents are as follows:

\subsection{Quality control of data collection}

In the data collection process data quality control should be noticed from a few aspects about the scientificity and practicability and use effect of the data system structure and data content, and should follow the following technical specifications:

1) Numbers and text collected must be accurate, the accuracy of data must reach $99.5 \%$;

2) Document data must be complete, detailed and accurate;

3 ) Numerical data are accurate, standardized, uniform units of measurement, and facilitate statistical analysis;

4) Data quality of graphics and image includes a measurement error (error of the system, operator error, accidental error) Mapping errors, digital error, editing error of correction and analysis, data conversion error is less than $0.5 \%$.

\subsection{Quality control of data entry}

Comply with national standards of existing data entry. For non-standard input, professional department is responsible for data entry rules. For data sources involved by data of multi-sector should be unified using a sector' $s$ data. In the data entry process we should timely inspect the quality of data entry, at the same time, also should take the following quality assurance measures:

1) Entry personnel qualification: Input rate of 100 words per minute or so, bit error rate is less than five out of 10,000 ; Strictly obey the input rules and operational procedures;

2) In accordance with the requirements of entry indicators, if the program can be used to control data entry, entry control procedures must be used;

3 ) Strengthen proofreading, improve the quality of data entry (manual re-recorded proof method, machine proofreading method);

4) Select to ensure the accuracy of the input device and related information carrier;

5) There is a perfect data management and quality inspection system;

6) Data on the scan input should check and conform to the degree of the real data, requiring graphics and images are clear, identification accuracy is above $99.5 \%$.

\subsection{Data Classification and Indexing Quality Control}

Classification indexing is a method of classification knowledge base on level enumerating method. It can more fully reflect the whole knowledge and its inner logical relationship. It is systematic, family of knowledge retrieval ability and enlarge/shrinkage function. "Shared platform" data classification indexing quality control to follow these guidelines: 
1) Since rural science and technology data resource type is various, content is wide, there is a variety of classification indexing scheme, but must provide a classification scheme choice, that is as "rural science and technology data classification and code" technical specification as the basis of classification indexing;

2) Categories and classification codes of indexing object are mandatory fields, must be marked with the contents (values), allows duplicate content to appears (multi-value) with duplicate content between the ":” character.

\subsection{Subject indexing of data quality control}

To ensure the effect of "Shared platform" data retrieval, data subject indexing is indispensable, the following subject indexing specification is adopted:

\subsubsection{Subject indexing method}

1) Subject indexing tool is selected. For example, the "Chinese Library Classification" , "Agricultural Professional Classification" , "Thesaurus of Agricultural Sciences" are as the word choice basis of subject indexing;

2) Strict enforcement word choice process of indexing work, word choice must be standard and accurate;

3 ) Fully considering overall and specificity of theme analysis, the maximum to meet the requirements of precision and recall;

4) Subject factors (the research object, material, method, process and conditions), common factor, location factor, time factor and data types constitute subject factors, we carry out the subject indexing from the above 5 factors;

5 ) Data of graphics, images and charts are indexed keywords which are connected in order to retrieving. Keyword choice must be standardized.

\subsubsection{Subject indexing rules}

1) Objectively reflect the information content, avoid introducing indexing personnel's personal views;

2) Keywords selected come from the thesaurus. Synonym keywords need to be converted into formal synonyms. Informal word cannot be used as indexing words;

3 ) When there is no specific corresponding keywords, you should choose the most directly related to a few keywords equipping indexing;

4) If the combination of indexing are still unable to meet the requirements, you should select the most direct hypernym Indexing;

5 ) If hypernym still not appropriate, you can use keywords indexing (free words);

6 ) Subject indexing depth is generally seven keywords (mean value), general indexing word are 5-10 keywords. 


\subsection{Subject indexing of data quality control}

\subsubsection{The data dictionary}

To facilitate data sharing, improve the efficiency of data use and development, reduce development costs, "Sharing Platform" need to build the data dictionary of rural science and technology to regulate data storage structure. Data dictionary should include the following:

\begin{tabular}{|c|c|}
\hline Data Item Name & Explanation \\
\hline Data System Name & $\begin{array}{l}\text { Name of data systems, such as rural science and } \\
\text { technology data sharing system }\end{array}$ \\
\hline The database name & The name of the database file \\
\hline Data Name & The name of the data item \\
\hline Data store name & The name of the data field \\
\hline The data type & $\begin{array}{l}\text { The type of data, such as digital type, character type, date } \\
\text { type, etc. }\end{array}$ \\
\hline $\begin{array}{l}\text { The length of the } \\
\text { data storage }\end{array}$ & Data stored in the computer space represented by byte \\
\hline Unit & Measurement Units of data (unit of measurement) \\
\hline Code description & the use of code system and coding rule \\
\hline Precision & Effective number of minimum digit position \\
\hline $\begin{array}{l}\text { The lower limit of } \\
\text { data }\end{array}$ & The reasonable lower limit of data \\
\hline $\begin{array}{l}\text { The upper limit of } \\
\text { data }\end{array}$ & The reasonable upper limit of data \\
\hline $\begin{array}{l}\text { Access to the } \\
\text { means of data }\end{array}$ & Data measurement methods or reference sources \\
\hline $\begin{array}{l}\text { Time and/or the } \\
\text { environment }\end{array}$ & The time of get data and / or the environment \\
\hline Remark & To add other instructions \\
\hline
\end{tabular}

\subsubsection{Data structure specification}

"Sharing platform" of agricultural science and technology data resource involves science and technology data of agriculture, forestry, water conservancy, meteorology and other fields. Data types have papers, books, journals, meetings, news, newspapers, patent information, policies and regulations, standards, non-book materials, etc. Data type is very complex, you should follow the following technical specifications in the design of the database's data structure:

1) Follow the international and domestic existing metadata standards; Or follow the

Dublin core element set; Or follow the MARC standard (USMARC, CNMARC); Or follow the "Geographic Information - Metadata" standard, (ISO 19115:2003, 
MOD, draft); Follow the "Metadata Specification of Rural Science Data Sharing Platform" based on the above criteria.

2) In the database of "Shared platform" the required data item is defined as: title, author, subject category, information source code, keywords, description, origin, date and ID number.

3 ) Data structure is designed to meet the requirements of rural science and technology data sharing system. Date structure has been recognized by experts in the relevant databases. Avoid arbitrariness of database structure definition.

4) Name of the data item must be standardized, meaning must be accurate.

\subsection{The technical specification of data description}

GB3793-83 in "Rural science and technology data resource sharing platform" is one of the cataloging rules must be obeyed.

\subsubsection{Data description of graphics and tables}

There are two rules of the cataloging rules of graphics and bibliographic data:

1 ) For powerful database systems such as Oracle, you can put graphical information, form data directly into the field.

2) For less powerful database systems such as SQL Server, you can use the link technology, through the fields of subject (key words) associated with graphics and tables.

\subsubsection{Data record consistency}

1) Information source name, organization name should be consistent;

2) Units of measurement should be consistent;

3 ) Description of special characters should be consistent;

4) Description of numbers and dates should be consistent

\subsubsection{Data record consistency}

"Sharing Platform" obey GB / T 17295-1998 international trade measurement unit code standards. Units of measurement appearing in Rural Science database must be strictly enforced this standard. Numeric database must have units of measurement instructions.

\section{Data quality control as a whole}




\subsection{Data quality control process}

Data quality control process is divided into self-examination, the quality control of a professional group and the overall group acceptance three stages. Each stage has its corresponding inspection standards, quality control flow chart below:

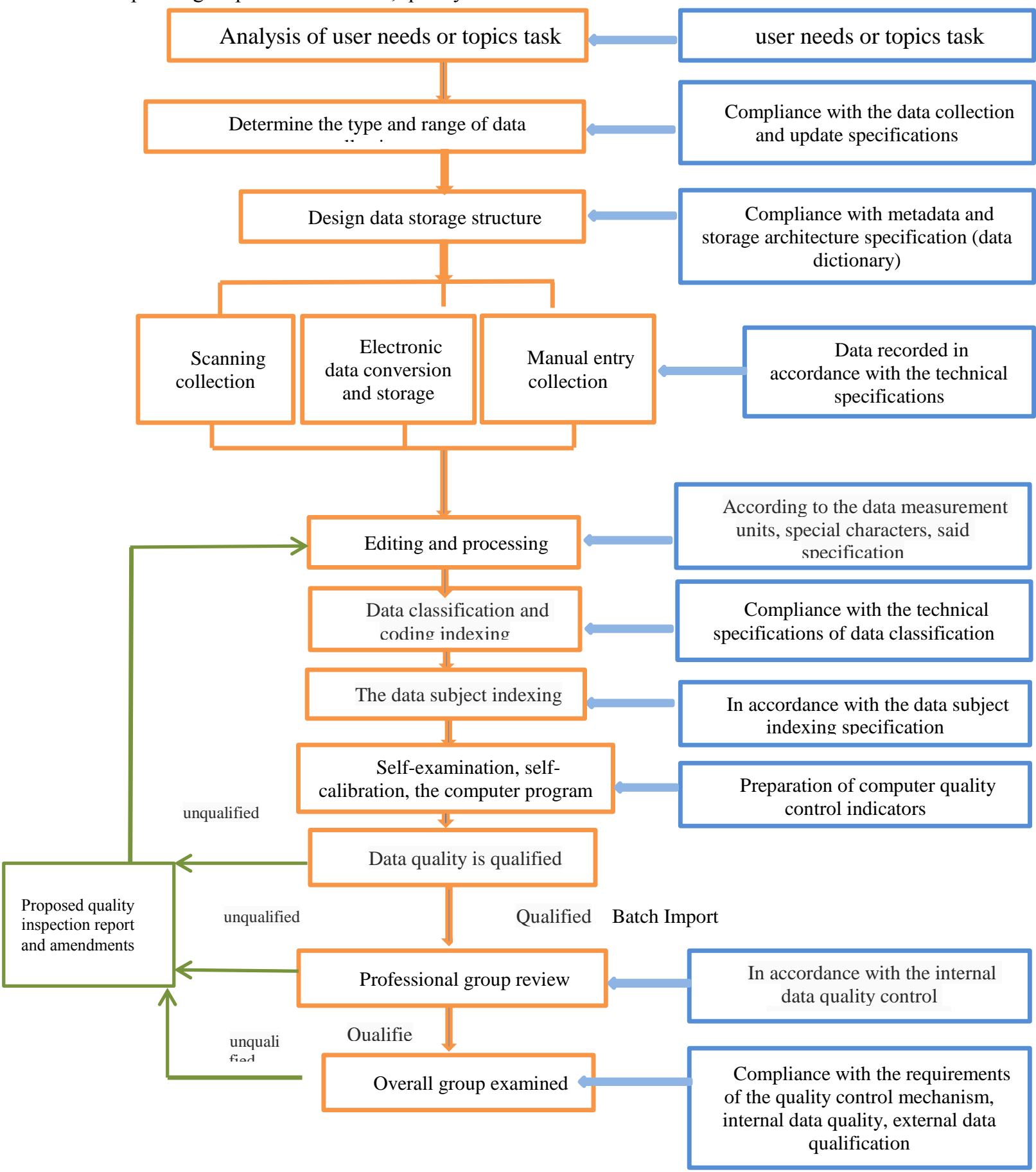




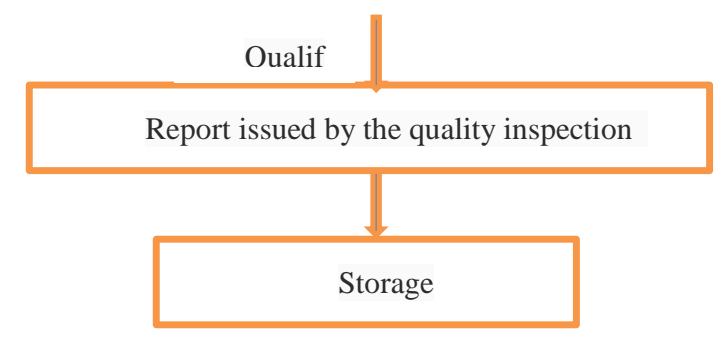

Fig. 1.

\subsection{Rural Science and Technology Data quality evaluation}

\begin{tabular}{|c|c|c|c|c|}
\hline $\begin{array}{l}\text { Order } \\
\text { number }\end{array}$ & $\begin{array}{l}\text { Evaluation } \\
\text { of the } \\
\text { project }\end{array}$ & Evaluation of Content & Evaluation basis & $\begin{array}{l}\text { Evaluati } \\
\text { on of } \\
\text { quantize } \\
\text { d values }\end{array}$ \\
\hline 1 & $\begin{array}{l}\text { Collectio } \\
\text { n scope }\end{array}$ & $\begin{array}{l}\text { 1. Defining the rationality of the } \\
\text { collection scope } \\
\text { 2. Defining the comprehensive of } \\
\text { the collection scope } \\
\text { 3. Defining the maneuverability } \\
\text { of the collection scope }\end{array}$ & $\begin{array}{ll}> & \text { user requirement } \\
> & \text { Project specification }\end{array}$ & 5 \\
\hline 2 & $\begin{array}{l}\text { Acquisiti } \\
\text { on methods }\end{array}$ & 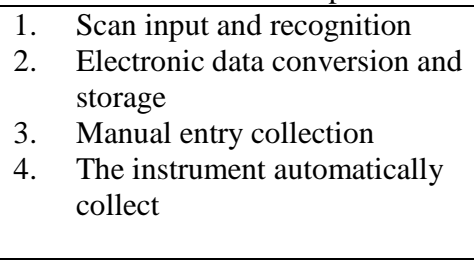 & $\begin{array}{l}>\text { Clarity of graphic and image } \\
>\text { The recognition accuracy of } \\
99 \% \\
>\quad \text { Manual entry error rate is less } \\
\text { than } 0.05 \% \\
>\quad \text { To ensure that the data } \\
\text { statistical error }\end{array}$ & 15 \\
\hline 3 & $\begin{array}{l}\text { The data } \\
\text { structure }\end{array}$ & 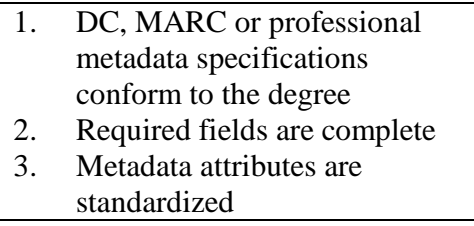 & $\begin{array}{l}>\text { Follow metadata standards } \\
>\text { Prescribed } 9 \text { required fields } \\
>\text { Eight properties of metadata }\end{array}$ & 15 \\
\hline 4 & $\begin{array}{c}\text { Data } \\
\text { description }\end{array}$ & $\begin{array}{l}\text { 1. The degree of compliance with } \\
\text { the data type record } \\
\text { specification } \\
\text { 2. Data record consistency } \\
\text { degree }\end{array}$ & $\begin{array}{l}>\text { Reference description standard } \\
\text { or description in the database } \\
\text { itself } \\
>\quad \text { Check the fields which has } \\
\text { requirement for statistics and } \\
\text { retrieve } \\
>\quad \text { In accordance with } \\
\text { international standards of } \\
\text { measurement } \\
>\text { Accordance with the } \\
\text { requirements of the special } \\
\text { characters said } \\
>\text { Description of the database }\end{array}$ & 20 \\
\hline
\end{tabular}




\begin{tabular}{|c|c|c|c|c|}
\hline & & & itself & \\
\hline 5 & \begin{tabular}{l}
\multicolumn{1}{c}{ Data } \\
classificatio \\
$n$
\end{tabular} & $\begin{array}{l}\text { 1. Classification system } \\
\text { prescribed by the State } \\
\text { 2. "Shared platform" } \\
\text { classification specification }\end{array}$ & $\begin{array}{l}>\text { Scientific of Category name } \\
>\text { The accuracy of classification } \\
\text { and coding } \\
>\text { The consistency of record }\end{array}$ & 10 \\
\hline 6 & $\begin{array}{l}\text { The data } \\
\text { subject } \\
\text { indexing }\end{array}$ & $\begin{array}{l}\text { 1. The thesauri stipulated by the } \\
\text { state } \\
\text { 2. "Shared platform" to provide } \\
\text { a scientific term } \\
\text { 3. Comprehensiveness and } \\
\text { technicality and subject } \\
\text { indexing }\end{array}$ & $\begin{aligned}> & \text { Reasonableness of the choice of } \\
& \text { words } \\
> & \text { Indexing depth control for } \\
& \text { seven keywords } \\
> & \text { The consistency of word choice } \\
> & \text { The degree of leakage }\end{aligned}$ & 10 \\
\hline 7 & $\begin{array}{l}\text { The data } \\
\text { content }\end{array}$ & $\begin{array}{l}\text { 1. Topics of data is reasonable } \\
\text { (over-range or missing } \\
\text { included) } \\
\text { 2. Scientific of data content } \\
\text { 3. Stability of data sources }\end{array}$ & $\begin{array}{l}\text { User needs } \\
\text { Project mission statement } \\
\text { Meet the qualification } \\
\text { requirements of the data } \\
\text { supplier }\end{array}$ & 20 \\
\hline 8 & $\begin{array}{l}\quad \text { Data } \\
\text { quality } \\
\text { control } \\
\text { mechanism }\end{array}$ & $\begin{array}{l}\text { 1. Data quality control } \\
\text { organization } \\
\text { 2. The organization staffing } \\
\text { 3. Stability of data quality } \\
\text { control personnel }\end{array}$ & $\begin{array}{l}>\text { Whether the establishment of } \\
\text { appropriate quality control } \\
\text { mechanism } \\
>\text { Quality control personnel's } \\
\text { knowledge structure is } \\
\text { reasonable } \\
>\text { The stability of the data quality } \\
\text { control personnel }\end{array}$ & 5 \\
\hline
\end{tabular}

\section{Data quality assessment report}

After the overall quality control of the data, you shall issue the corresponding data quality assessment report. The content includes: the report name, data content review, the unit responsible for the data, data quality assessment, the person completing the report, the evaluation unit, reporting to fill time.

\section{Application}

This paper discusses the standard of data quality control technology has been used in China Agricultural Science and Technology Information Website and China Rural Science Information Website and other large national websites. These websites' data collection, data input, subject indexing, data storage construction, data description and data unit was prescribed. After these years of operation, these websites data quality control very well, these websites ranked among the best in the field of domestic agricultural websites. 


\section{Acknowledgment}

The work is supported by the special fund project for Basic Science Research Business Fee "Website of CAAS content resources organizations and service models research", AII (No. 2014-J-008).

\section{References}

1. Zhangxiaolin. Metadata Research and Application. Beijing. Beijing Library Press, 2002

2. Shaoquanqin. Several Key Issues in GIS Database Development. Acta Geographica Sinica.1995. Supplement: 34-42

3. Huajipeng. The Quality Control Method of Collecting Product Data. Applications of The Computer Systems. 2003(01): 77-79

4. Liangliping,Wuyang. Verification and Quality monitoring of Information Network Data.Chinese Journal of Hospital Statistics, 2003(03):192

5. Fang Youlin, Yang Dongqing, Tang Shiwei, Zhang Weihua, Yu Libo, Fu Qiang.Data Quality Managements in Data Warehouse. ,Computer Engineering and Applications, 2003(13):1-4

6. Luo Man. Quality Control of Open Databases. China Intelligence Information, 1994(02):31 